\title{
Characteristics and Coronavirus Anxiety Levels of Endodontic Patients During the Covid-19 Pandemic
}

\author{
Parla Meva Durmazpinar ${ }^{1}$, Guzide Pelin Sezgin ${ }^{2}$ \\ 1 Marmara University, Faculty of Dentistry, Department of Endodontics, Istanbul, Turkey. \\ 2 Biruni University, Faculty of Dentistry, Department of Endodontics, Istanbul, Turkey \\ Correspondence Author: Parla Meva Durmazpinar \\ E-mail: parlamewa @hotmail.com \\ Received: $18.05 .2021 \quad$ Accepted: 23.06 .2021
}

\begin{abstract}
Objective: The aim of this study was to determine the characteristics and coronavirus anxiety levels of patients who applied to an endodontics clinic in Turkey during the Covid-19 pandemic.

Methods: A total of 212 patients who applied to an endodontics clinic between January 1 and 31 2021, were asked to complete a questionnaire that included demographic information, Covid-19 history, anxiety history, and coronavirus anxiety scores. After the patients were examined by an endodontist, their complaint, pain level-using the Verbal Numerical Rating Scale (VNRS)—clinical findings, periapical index score (PAI), and endodontic diagnosis were recorded. Data was analyzed using descriptive statistical methods, while the Chi-square test, Fisher's Exact test, Fisher Freeman Halton test, and Yates Continuity Correction were used for the comparison of the qualitative data (significance level, $\mathrm{P}<0.05$ ).

Results: About half of the patients (43.4\%) were diagnosed with symptomatic irreversible pulpitis. The mean of the VNRS was $4.17 \pm 3.14$ with a median of 4 . Approximately $43 \%$ of the patients' PAl scores were 1 , which radiologically indicates normal periapical structures. When patients' coronavirus anxiety scores were evaluated, $86.8 \%$ were categorized as non-disordered and $13.2 \%$ as disordered.
\end{abstract}

Conclusion: Patients tended to visit an endodontics clinic usually for urgent procedures and postponed other dental procedures due to anxiety related to the Covid-19 pandemic in Turkey.

Keywords: Covid-19 pandemic, coronavirus anxiety scale, endodontic diagnosis, verbal numerical rating scale

\section{INTRODUCTION}

The Covid-19 epidemic emerged in Wuhan, China, at the end of 2019 and became an important health problem affecting the world in a short period of time $(1,2)$. The speed and type of reactions to this disease varied according to countries' different health systems, economics, and political ideologies (3). Daily life has changed, and many measures have been taken, including social isolation, closure of schools, and quarantine of societies, to deal with the pandemic (4). After the announcement of the first case in Turkey on March 10, 2020 , cases rose rapidly (5). Routine dental practices were suspended in mid-March. Organizations such as the World Health Organization and the American Dental Association recommended that only dental treatments that fall under the definition of emergency be undertaken $(2,5)$. The Turkish Ministry of Health also made this recommendation (6). Once the process of returning to normal life began in June 2020, routine dental procedures commenced once again in Turkey. Inaccurate information about the pandemic, the rapid increase in the number of infected and deaths, changes in work routines caused stress, anxiety and fear in the population
(7-9). It was reported that the Covid-19 pandemic period and the lockdown affected patients' anxiety levels and willingness to make dental appointments. Unconcerned patients were willing to go to dental appointments while anxious patients stated that they preferred to go to the dentist only in the case of emergencies (10). Recently, the Coronavirus Anxiety Scale (CAS) - a brief mental health screener-was developed by Lee (11) to fill a void in the mental health response to the growing public health crisis related to Covid-19. A Turkish validity and reliability study of the CAS was performed by Biçer et al. (12).

In this study, we aimed to examine the characteristics of patients, including symptoms, pain grades, radiological findings, coronavirus anxiety levels, and the diagnoses they received, who applied to an endodontics clinic between certain dates during the pandemic. To the best of our knowledge, there is currently no study on this subject in the literature. 


\section{METHODS}

This study was approved by the ethical board of Izmir Democracy University (no: 2020/24-2). Patients' participation in this study was voluntary and anonymous. This study was also conducted in compliance with the Helsinki Declaration of 2013. A pilot study was performed on 25 randomly selected patients to validate the questionnaire, and its Cronbach's alpha value was determined to be $87.6 \%$. The pilot study responses were excluded from the final study.

The study population consisted of patients who were referred to the Endodontics Department of Biruni University between January 1 and 31 2021. A total of 212 patients over the age of 13 who applied to the endodontics clinic and agreed to participate in the study, after having passed through the triage area, were included in the investigation. The patient evaluation form consisted of three parts with 25 questions. The first part involved demographic information and questions related to the Covid-19 history of patients (13 questions). The second part questioned the history of anxiety and anxiety levels related to Covid-19 using the CAS (9 questions) (11). In the last part (3 questions), an endodontist recorded the patient complaint, pain level using the Verbal Numerical Rating Scale (VNRS) (13), clinical findings, radiological signs using the periapical index score (PAI) (14), and the endodontic diagnosis. A 5-point Likert scale was used in the CAS, which consisted of five questions and one dimension. Total anxiety level was calculated on the basis of each patients' response. According to this, the highest score obtained from the scale was 20. Scores of 9 and above were interpreted as coronavirus anxiety disordered while scores below 9 were categorized as non-disordered (11). All procedures were performed by a single endodontist.

\subsection{Statistical Analysis}

The IBM SPSS Statistics 22 (IBM SPSS, Turkey) program was used for the statistical analysis. Data normality was evaluated using the Shapiro Wilks test. Data were analyzed using descriptive statistical methods (mean, standard deviation, frequency). The Chi-square test, Fisher's Exact test, Fisher Freeman Halton test, and Yates Continuity Correction were used to compare the qualitative data. Cronbach's alpha coefficient was calculated for the scale reliability. Significance was evaluated at the $p<0.05$ level.

\section{RESULTS}

The demographic information of the patients is given in Table 1. Approximately $24 \%$ of participants in the study lived with someone in the Covid-19 risk group, and $13.2 \%$ of them stated that they were in close contact with a person who was Covid-19 positive. $10.4 \%$ of the patients had been diagnosed with Covid-19, 90.9\% had experienced mild symptoms, and 9.1\% had experienced severe symptoms. 68.9\% reported that they had relatives or friends in their close circle who had tested positive for Covid-19. About $15 \%$ had lost a relative or friend (Table 2).

\begin{tabular}{|c|c|c|c|}
\hline & & $\mathrm{n}$ & $\%$ \\
\hline \multirow[t]{6}{*}{ Age } & $13-25$ & 66 & 31,1 \\
\hline & $26-35$ & 70 & 33,0 \\
\hline & $36-45$ & 34 & 16,0 \\
\hline & $46-55$ & 26 & 12,3 \\
\hline & $56-64$ & 10 & 4,7 \\
\hline & $65+$ & 6 & 2,8 \\
\hline \multirow[t]{2}{*}{ Sex } & Male & 82 & 38,7 \\
\hline & Female & 130 & 61,3 \\
\hline \multirow[t]{5}{*}{ Education status } & Elementary school & 32 & 15,1 \\
\hline & Middle school & 32 & 15,1 \\
\hline & High school & 70 & 33,0 \\
\hline & Undergraduate & 60 & 28,3 \\
\hline & Postgraduate & 18 & 8,5 \\
\hline \multirow[t]{2}{*}{ Maritial Status } & Married & 126 & 59,4 \\
\hline & Single & 86 & 40,6 \\
\hline \multirow[t]{2}{*}{ Children } & Yes & 114 & 53,8 \\
\hline & No & 98 & 46,2 \\
\hline \multirow[t]{5}{*}{ Chronic diseases } & No & 156 & 73,6 \\
\hline & Hypertension & 10 & 4,7 \\
\hline & Diabetes & 6 & 2,8 \\
\hline & КОАН & 10 & 4,7 \\
\hline & Others & 30 & 14,1 \\
\hline
\end{tabular}

Table 2. The distribution of participants' responses to questions about their Covid-19 history

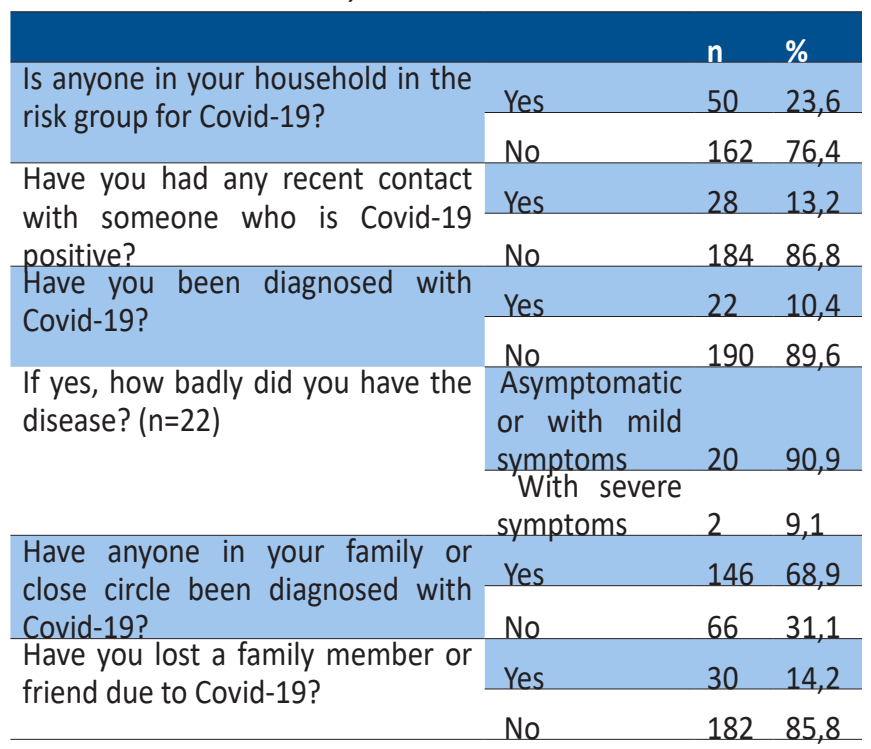

A total of $14.2 \%$ of the patients stated that they had previously been diagnosed with an anxiety disorder by a psychologist. The rate of delaying dental appointments due to the pandemic of those who had been previously diagnosed 
with an anxiety disorder by a psychiatrist (80\%) was found to be statistically significantly higher than those who had not (53.8\%) (p:0.013; p<0.05).

The distribution of the CAS questions and the answers given by the patients are summarized in Table 3 . The Cronbach's alpha coefficient of the scale was $87.6 \%$. According to the CAS, a total of $184(86,8 \%)$ patients were categorized as non-disordered and 28 (13.2\%) as disordered.

Table 3. Responses given to the CAS

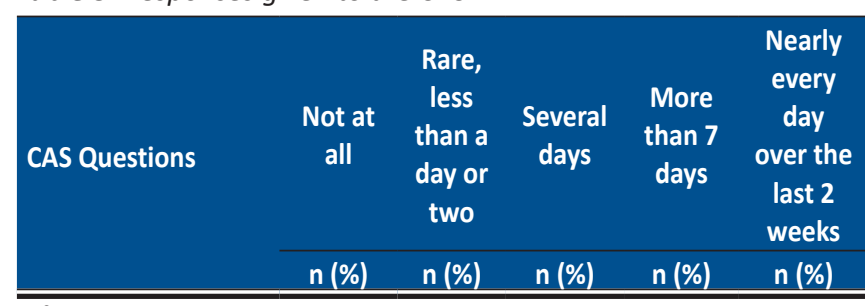

I felt dizzy,

lightheaded, or faint,

when I read or

listened to

$\begin{array}{llll}160 & 16 & 22 & 14\end{array}$

news about the

$(\% 75,5) \quad(\% 7,5) \quad(\% 10,4) \quad(\% 6,6)$

coronavirus.

\begin{tabular}{|c|c|c|c|c|c|}
\hline $\begin{array}{l}\text { I had trouble falling } \\
\text { or staying asleep } \\
\text { because I was } \\
\text { thinking about the } \\
\text { coronavirus. }\end{array}$ & $\begin{array}{c}152 \\
(\% 71,7)\end{array}$ & $\begin{array}{c}16 \\
(\% 7,5)\end{array}$ & $\begin{array}{c}26 \\
(\% 12,3)\end{array}$ & $\begin{array}{c}14 \\
(\% 6,6)\end{array}$ & $4(\% 1,9)$ \\
\hline $\begin{array}{l}\text { I felt paralyzed } \\
\text { or frozen when I } \\
\text { thought about or } \\
\text { was } \\
\text { exposed to } \\
\text { information about } \\
\text { the coronavirus.. }\end{array}$ & $\begin{array}{c}178 \\
(\% 84)\end{array}$ & $\begin{array}{c}10 \\
(\% 4,7)\end{array}$ & $\begin{array}{c}12 \\
(\% 5,7)\end{array}$ & $6(\% 2,8)$ & $6(\% 2,8)$ \\
\hline $\begin{array}{l}\text { I lost interest in } \\
\text { eating when I } \\
\text { thought about or } \\
\text { was } \\
\text { exposed to } \\
\text { information about } \\
\text { the coronavirus. }\end{array}$ & $\begin{array}{c}136 \\
(\% 64,2)\end{array}$ & $\begin{array}{c}26 \\
(\% 12,3)\end{array}$ & $\begin{array}{c}18 \\
(\% 8,5)\end{array}$ & $\begin{array}{c}26 \\
(\% 12,3)\end{array}$ & $6(\% 2,8)$ \\
\hline $\begin{array}{l}\text { I felt nauseous } \\
\text { or had stomach } \\
\text { problems when I } \\
\text { thought about or } \\
\text { was exposed to } \\
\text { information about } \\
\text { the coronavirus. }\end{array}$ & $\begin{array}{c}154 \\
(\% 72,6)\end{array}$ & $\begin{array}{c}22 \\
(\% 10,4)\end{array}$ & $\begin{array}{c}12 \\
(\% 5,7)\end{array}$ & $\begin{array}{c}18 \\
(\% 8,5)\end{array}$ & $6(\% 2,8)$ \\
\hline
\end{tabular}

The patient complaints and endodontic diagnoses are shown in Table 4. According to this, patients were diagnosed with symptomatic irreversible pulpitis $(43.4 \%)$, chronic apical periodontitis $(23.6 \%)$, other diagnoses $(8.5 \%)$, pulp necrosis or gangrene $(7.5 \%)$, reversible pulpitis $(5.7 \%)$, chronic apical abscess $(5.7 \%)$, acute apical abscess $(4.7 \%)$, and traumarelated injury $(0.9 \%)$. The distribution of clinical findings and PAl scores is shown in Table 5.
Table 4. The patient complaints and endodontic diagnoses

\begin{tabular}{|c|c|c|}
\hline Patient Complaint & n & $\%$ \\
\hline Pain at night & 50 & 23,6 \\
\hline Spontaneous pain & 50 & 23,6 \\
\hline Pain with hot and/or cold & 68 & 32,1 \\
\hline Pain when chewing & 96 & 45,3 \\
\hline Routine control and/or follow up & 30 & 14,2 \\
\hline Asymptomatic & 28 & 13,2 \\
\hline Other (trauma etc.) & 10 & 4,7 \\
\hline Diagnosis & n & $\%$ \\
\hline Reversible pulpitis & 12 & 5,7 \\
\hline Symptomatic irreversible pulpitis & 92 & 43,4 \\
\hline Chronic apical abscess & 12 & 5,7 \\
\hline Chronic apical periodontitis & 50 & 23,6 \\
\hline Acute apical abscess & 10 & 4,7 \\
\hline Traumatic dental injury & 2 & 0,9 \\
\hline Pulp necrosis or gangrene & 16 & 7,5 \\
\hline $\begin{array}{l}\text { Other (Endodotic treatment indication for } \\
\text { prosthetic reasons etc.) }\end{array}$ & 18 & 8,5 \\
\hline
\end{tabular}

Table 5. Clinical Findings and PAI Score

\begin{tabular}{ll} 
Clinical Findings & $\mathbf{n} \%$ \\
\hline Percussion pain & 14267 \\
\hline Palpation pain & 125,7 \\
\hline Positive Vitality & 10851 \\
\hline Sinus tract & 62,8 \\
\hline Intraoral abscess & 125,7 \\
\hline Extraoral abscess & 20,9 \\
\hline PAI Score & $\mathbf{n} \%$ \\
\hline 1 & 9042,5 \\
\hline 2 & 5425,5 \\
\hline 3 & 4822,6 \\
\hline 4 & 104,7 \\
\hline 5 & 104,7 \\
\hline
\end{tabular}

The VNRS ranged from 0 to 10 , with a mean of $4.17 \pm 3.14$ and a median of 4 . The VNRS scores of patients aged 56 and over was found to be significantly lower than those of the 13-25 and 26-35 age groups (p1: 0.012; p2: 0.013; $\mathrm{p}<0.05)$. The VNRS scores of patients with acute apical abscess and symptomatic irreversible pulpitis were found to be significantly higher than those with pulp necrosis or gangrene, trauma-related injury, chronic apical abscess, reversible pulpitis, chronic apical periodontitis, and other diagnoses $(p<0.05)$.

The disordered rate of coronavirus anxiety among women (18.5\%) was statistically significantly higher than that of men (4.9\%) ( $p: 0.008 ; p<0.05)$. The coronavirus anxiety disordered rate of undergraduate graduates $(26.7 \%)$ was found to be statistically significantly higher than that of secondary school graduates $(6.3 \%)$ and high school $(5.7 \%)$ graduates ( 1 : 0.038; p2: 0.002; $p<0.05)$. 
Table 6. Comparison of corona anxiety levels according to Covid-19 history, anxiety disorder and postponing dental treatment appointments

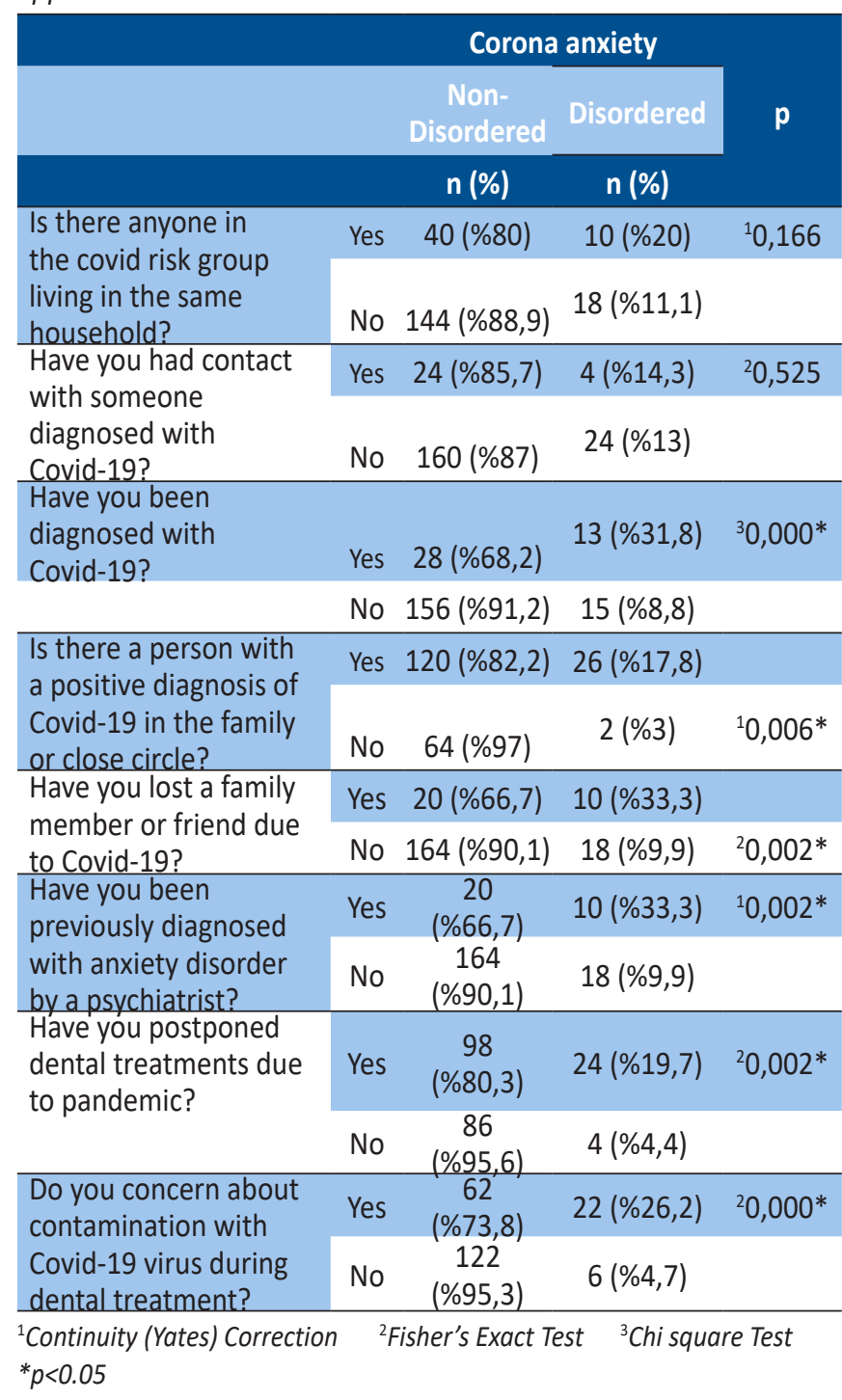

More than half of patients (57.5\%) had postponed their dental treatments due to the pandemic, and $39.6 \%$ were concerned about the transmission of Covid-19 during dental treatment. The non-disordered status of those who had not been diagnosed with Covid-19 was found to be significantly higher than those who had been ( $p 1$ : 0.000; p2: $0.001 ; p<0.05)$. The disordered rate of coronavirus anxiety was found to be significantly higher in those who had experienced a positive diagnosis of Covid-19 in their family or close environment (17.8\%) than those who had not (3\%) ( $p: 0.006 ; p<0.05)$. In addition, the coronavirus anxiety disordered rate of patients who had lost a family member or friends due to Covid-19 (33.3\%) was found to be significantly higher than those who had not $(9.9 \%)$ ( $p: 0.002 ; p<0.05)$. The coronavirus anxiety disordered rate of patients who had been previously diagnosed with an anxiety disorder by a psychiatrist (33.3\%) was found to be statistically significantly higher than those who had not received such a diagnosis (9.9\%) ( $p: 0.002 ; p<0.05)$. Moreover, the coronavirus anxiety disordered rate of those who were concerned about the transmission of Covid-19 during dental treatments (26.2\%) was found to be significantly higher than those who were not (4.7\%) ( $p: 0.000 ; p<0.05)$. The coronavirus anxiety disordered rate of patients who had postponed dental treatments due to the pandemic (19.7\%) was found to be significantly higher than that of those who had not (4.4\%). Approximately $67 \%$ of patients who had been previously diagnosed with an anxiety disorder were concerned about the transmission of the virus during dental treatments, which was significantly higher than those who had not been diagnosed with an anxiety disorder (p:0.002; p<0.05) (Table 6).

\section{DISCUSSION}

Pulpal and periapical lesions were found to be the most common reason for emergency dental visits in China during the Covid-19 pandemic (15). A study that researched the characteristics of endodontic emergencies remarked that symptomatic irreversible pulpitis was the most common disease (16). Similarly, in our study, most of the patients who applied to the endodontics clinic were diagnosed with symptomatic irreversible pulpitis and had normal periapical structures based on their PAI scores. The VNRS scores of patients with symptomatic irreversible pulpitis and acute apical abscess were found to be significantly higher than for other diseases. This result is also in agreement with the study of Yu et al. (16). Patients mostly applied to our clinic with percussion pain $(67 \%)$, hot-cold sensitivity $(32,1 \%)$, spontaneous pain (23.6\%), and night pain (23.6\%). Moreover, in the present study, only 2 out of 212 patients had traumarelated injuries, which might be due to the limitations imposed on outdoor activities during the pandemic. This result is similar to the findings of recent literature (15).

The majority of patients who participated in this study were in the non-disordered category in terms of coronavirus anxiety levels. Based on this finding, it can be said that some dental patients were concerned about Covid-19 in Turkey, but this concern was not at a level that suggested illness or required psychological support. A possible reason for this may be because the study was conducted later in the pandemic, and over time, most people may have become used to living with it. Patients who are already less anxious may also be more comfortable going to dental clinics. Since there are no studies in the literature that examine the coronavirus anxiety levels of patients visiting dental clinics, we cannot compare the results.

In this study, the relationship between the study parameters and patients' coronavirus anxiety status was also examined. According to the gender comparison, the coronavirus anxiety levels of women were higher than those of men. Consistent with our results, Cotrin et al. (17) found that women were more anxious than men about the Covid-19 pandemic. Interestingly, in our study, most patients who visited the endodontics clinic were women. Similarly, Peloso et al. (10) stated in their study that, although women were more anxious about the pandemic than men, they were more willing to go to the dentist. This may be because female patients are more 
compatible with dental treatments than men, as reported by Demetriou et al. (18). Considering patients' education levels, it was found that those with bachelor's degrees had a higher coronavirus anxiety disorder status than those with high school and secondary school diplomas. Based on this result, it may be that patients with a higher level of education are more susceptible to anxiety disease due to their greater knowledge about the pandemic.

It is remarkable that the coronavirus anxiety levels of patients who had family members or close relatives who had been diagnosed with Covid-19 were higher than those who had not, even though most of these patients and their relatives had experienced mild symptoms. In our opinion, this may be due to other factors, such as educational status, business conditions, socio-economic situation, or a pre-existing anxiety disorder that triggered coronavirus anxiety. Our results also indicate that some patients had been previously diagnosed with anxiety disorders by a psychologist, and they were likelier to delay their appointments.

In this study, most of the patients who applied to the endodontics clinic declared that they did not have any chronic diseases. This situation can be explained by the fact that patients with chronic diseases do not like to go to the dentist. In other words, patients with chronic illnesses and coronavirus anxiety may delay their dentist appointments.

According to the results of this study, the coronavirus anxiety levels of patients previously diagnosed with an anxiety disorder were found to be higher, which may indicate that patients with a previous history of anxiety experienced increased anxiety associated with the coronavirus pandemic.

Although this study was not conducted at the beginning of the pandemic, when there was relatively greater uncertainty, it was determined that most of the patients who applied to the endodontics clinic postponed their dental appointments, and most of them applied only in the case of emergencies. The main reasons for this included worry about being infected with Covid-19 during dental treatment and/or coronavirus anxiety. Other possible causes may be a prior anxiety history and the socio-economic conditions of patients.

The limitation of the present study is that it included a limited population over a limited time frame. Future studies could be conducted with a larger sample to investigate the characteristics of endodontic patients and their coronavirus anxiety status.

\section{CONCLUSION}

It was seen that some patients postponed their dental treatments due to anxiety related to the Covid-19 pandemic, applying to endodontics clinics for emergency treatments only. This situation may result in a growth in dental problems after the Covid-19 pandemic ends due to the delay in seeking preventive and conservative treatments. Since it is uncertain how long the pandemic will last, performing both emergency and routine dental treatments are essential for the oral and dental health of individuals. It is important to eliminate the concerns of patients that cause them to delay their dental appointments.

\section{REFERENCES}

[1] Li Q, Guan X, Wu P, Wang X, Zhou L, Tong Y, Feng Z. Early transmission dynamics in Wuhan, China, of novel coronavirusinfected pneumonia. N Engl J Med 2020; 382: 1199-1207.

[2] Phelan AL, Katz R, Gostin LO. The novel coronavirus originating in Wuhan, China: challenges for global health governance. JAMA 2020; 323: 709-710.

[3] Coulthard, P. Dentistry and coronavirus (COVID-19)-moral decision-making. Br. Dent. J 2020; 228: 503-505.

[4] Shanafelt T, Ripp J, Trockel M. Understanding and addressing sources of anxiety among health care professionals during the COVID-19 pandemic. JAMA 2020; 323: 2133-2134.

[5] World Health Organization - WHO Clinical management of severe acute respiratory infection when novel coronavirus (nCoV) infection is suspected. WHO/2019-nCoV/ clinical/2020.4.

[6] Turkish Dental Association - Dişhekimliğinde Acil UygulamalarT.C. Sağlık Bakanlığı Sağlık Kurumlarına Yönelik Alınacak Uygulamaların Belirlenmesi 2020. Available from: http://www. tdb.org.tr/icerik_goster.php?Id=3427

[7] Lei L, Huang X, Zhang S, Yang J, Yang L, Xu M. Comparison of prevalence and associated factors of anxiety and depression among people affected by versus people unaffected by quarantine during the COVID-19 epidemic in Southwestern China. Med Sci Monit 2020; 26: e924609-1-e924609-12.

[8] Liu S, Yang L, Zhang C, Xiang YT, Liu Z, Hu S, Zhang B. Online mental health services in China during the COVID-19 outbreak. The Lancet Psychiatry 2020; 7: 17-18.

[9] Ornell F, Schuch JB, Sordi AO, Kessler FHP. "Pandemic fear" and COVID-19: mental health burden and strategies. Braz. J. Psychiatr 2020; 42: 232-235.

[10] Peloso RM, Pini NIP, Sundfeld Neto D, Mori AA, Oliveira RCGD, Valarelli FP, Freitas KMS. How does the quarantine resulting from COVID-19 impact dental appointments and patient anxiety levels? Braz. Oral Res. 2020; 34: 84-94.

[11] Lee SA. Coronavirus Anxiety Scale: A brief mental health screener for COVID-19 related anxiety. Death Stud 2020; 44: 393-401.

[12] Biçer I, Çakmak C, Demir H, Kurt ME. Koronavirüs Anksiyete Ölçeği Kısa Formu: Türkçe Geçerlik ve Güvenirlik Çalışması. Anatol Clin 2020; 25: 216-225. (Turkish)

[13] Daoust R, Beaulieu P, Manzini C, Chauny JM, Lavigne G. Estimation of pain intensity in emergency medicine: a validation study. Pain 2008; 138: 565-570.

[14] Ørstavik D, Kerekes K, Eriksen HM. The periapical index: a scoring system for radiographic assessment of apical periodontitis. Endod Dent Traumatol 1986; 2: 20-24.

[15] Guo H, Zhou Y, Liu X, Tan J. The impact of the COVID-19 epidemic on the utilization of emergency dental services. J. Dent. Sci 2020; 15: 563-567.

[16] Yu J, Zhang T, Zhao D, Haapasalo M, Shen Y. Characteristics of endodontic emergencies during COVID-19 outbreak in Wuhan. J. Endod 2020; 46 : 730-735. 
[17] Cotrin P, Peloso RM, Oliveira RC, Pini NIP, Valarelli FP, Freitas KMS. Impact of coronavirus pandemic in appointments and anxiety/concerns of patients regarding orthodontic treatment. Orthod Craniofac Res 2020; 23: 455-461.
[18] Demetriou N, Tsami-Pandi A, Parashis A. Compliance with supportive periodontal treatment in private periodontal practice. A 14-year retrospective study. J. Periodontol 1995; 66: $145-149$

How to cite this article: Durmazpinar PM, Sezgin GP. Characteristics and Coronavirus Anxiety Levels of Endodontic Patients During the Covid-19 Pandemic. Clin Exp Health Sci 2021; 11: 648-653. DOI: 10.33808/ clinexphealthsci.938847 